This article was published in International Wood Products Journal, 5, 161-167, 2014

http://dx.doi.org/10.1179/2042645314y.0000000074

\title{
Development of phenol-formaldehyde resin with low formaldehyde emissions that respects LEEDcertification
}

N. T. Paiva*1,2,3 , J. Pereira ${ }^{1,3}$, J. M. Ferra ${ }^{2}$, J. Martins ${ }^{1,4}$, L. Carvalho $^{1,4}$ and F. D. Magalhães ${ }^{1}$

${ }^{1}$ LEPAE, Chemical Engineering Department, Faculty of Engineering, University of Porto, Rua Dru Roberto Frias, 4200-465, Porto, Portugal

2EuroResinas - Industrias Químicas, S.A., 7520-195, Sines, Portugal

${ }^{3}$ ARCP - Association of Competence in Polymer Network, Rua Dru Roberto Frias, 4200-465, Porto, Portugal

${ }^{4}$ DEMad - Department of Wood Engineering, Polytechnic Institute of Viseu, Campus Politécnico de Repeses, 3504-510 Viseu, Portugal

*Corresponding author, email paiva.nadia@fe.up.pt

In the last years, production of particleboards with good overall performance and very low formaldehyde emission has been a challenge to wood based panels (WBP) industry, mainly since the re-classification of formaldehyde by the IARC (International Agency for Research on Cancer) as 'carcinogenic to humans (Group 1)'. Moreover, a new important limitation to the use of formaldehyde-based resins has been recently imposed by the LEED (Leadership in Energy and Environmental Design) certification for 'Green Building' construction: 'wood composites must contain no added urea-formaldehyde resins'. In this context, the main purpose of this study is to develop a PF resin for particleboard production that fulfils formaldehyde emission restrictions and LEED criteria, while presenting appropriate reactivity and bond strength. The mechanical performance and formaldehyde emissions of particleboards were optimized, changing both the resin synthesis and board production procedures. The synthesis process of these resins was carried out under an alkaline environment, and with an excess of formaldehyde towards phenol, in order to produce resol-type PF resins. The effect of changing the amount of added sodium hydroxide was studied. The particleboard production parameters were also changed, both in terms of blending conditions (amount of hardener and resin) and hot-pressing conditions (pressing time). A PF resin with very good internal bond strength, low formaldehyde strength and reasonable board pressing times was obtained using the following conditions: sodium hydroxide amount of $9 \%$ during the synthesis process, and 10\% hardener (based on oven-dry weight of resin) together with gluing factor between $4-5$ and $5 \%$ on the core layer during particleboard production. The best performing resin obtained demonstrated to be appropriate for use in the so called 'Green Building' construction. 


\section{Introduction}

The wood based panels industry has achieved production of panels with very low formaldehyde emissions keeping a good overall physical-mechanical performance, in response to the IARC's (International Agency for Research on Cancer) classification of formaldehyde as 'carcinogenic to humans (Group 1)' (IARC 2006). Most recently, in June 2011, the U.S. Department of Health and Human Services has listed formaldehyde as a known human carcinogen. Formaldehyde was also listed in the 12th Report on Carcinogens, compiled by the National Toxicology Program (USDHHS, 2011). However, a new important challenge has been recently imposed by LEED (Leadership in Energy and Environmental Design) certification, implying the absence of adhesives with urea-formaldehyde chemical bonds in 'Green Building' construction (LEED 2011).

LEED certification is the recognized standard for measuring building sustainability. Achieving LEED certification is the best way to demonstrate that a building project is truly 'green'. The LEED green buildings rating system is designed to promote design and construction practices that increase profitability while reducing the negative environmental impacts of buildings and improving occupant health and well being. In our case the sector of LEED certification that is applied is the LEED for commercial interiors, which promotes the construction of sustainable buildings that meet a set of environment preservation and human health quality goals. Minimizing indoor air contamination associated to substances that are odorous, irritating, and/or harmful to the comfort and well being of installers and occupants is one of the objectives (LEED 2011).

In this context possible alternatives to urea-formaldehyde (UF) resins are melamineformaldehyde (MF), melamine-phenol-formaldehyde (MPF) and phenol-formaldehyde (PF) resins. So the last group of resins was the one used in this study.

PF resins are the polycondensation products of the reaction of phenol with formaldehyde and they were the first true synthetic polymers to be developed commercially (Pizzi 2003). Since their first production in 1910 they have been developed enormously and they remain one of the more important products of the plastic industry (Whitehouse et al. 1967). Global phenolformaldehyde resin consumption grew at an average annual rate of less than $1 \%$ during 2007 2010 (but fell during 2007-2009). The overall weak global economy had a large negative impact on total phenol-formaldehyde resin consumption during 2007-2009, hitting the construction industry particularly hard in 2008 and 2009. However, the industry had started its road to recovery by year-end 2009, and in 2010 made a significant comeback as the world economy improved (SRI 2013).

Depending on the $\mathrm{F} / \mathrm{P}$ molar ratio and the $\mathrm{pH}$ used during the condensation step, the final phenol condensation products can be resol or novolac resins. Resols are obtained as a result of alkaline catalysis and an excess of formaldehyde, which means that F/P greater than 1 (Fig. 1). Heating causes the reactive methylol groups present in resol resins to condense to form larger molecules, a result achieved without the addition of a substance containing reactive methylene (or substituted methylene) groups (Pizzi 2003; Knop and Scheib 1979). On the other hand, Novolac resins are produced with an acidic catalyst and with a deficiency in formaldehyde, which means that F/P is lower than 1 (Fig. 1). This type of resins has no reactive methylol groups and therefore incapable of condensing with other novolac molecules on heating without the addition of hardening agents (Pizzi 2003; Knop and Scheib 1979). 
The biggest differences between acid and alkaline catalysis present in the PF synthesis process are: rate of reaction between formaldehyde and phenol, methylol- phenol condensation and the nature of the condensation products (Pizzi 2003). Hydrochloric acid is the most interesting case of acid catalyst, as well as oxalic acid and phosphoric acid (Martin 1956). For alkaline catalysis, sodium hydroxide (Caesar and Sachanen 1948), ammonia and hexamine (Kamoun and Pizzi 2000a; Kamoun and Pizzi 2000b) can be used. The catalyst concentration is important in the case of acidic catalysis, mostly affecting the reaction rate. Phenol-formaldehyde resins are used to make a variety of products including consolidated wood products such as plywood, engineered lumber, hard board, fiberboard and oriented strand board for exterior applications. Other products include fiberglass insulation, laminates, abrasive coatings, friction binders, foams, foundry binders and petroleum recovery binders (Fink, 2005). Wood adhesives will continue to have the largest share (about 33\%) of the world market for phenolic resins and will drive phenolic resin consumption on a global scale. The developing regions of Central and South America and Central and Eastern Europe will experience the largest growth in this application. Phenolic resin consumption for moulding compounds (accounting for about $20 \%$ of world consumption) will grow primarily in China and Other Asia as more moulding operations start up in the region. Laminates account for about 28\% of the world market (SRI 2013). In this work, the purpose is to produce particleboard for interior applications with this type of resins, more properly with PF resol resins. Some studies have been made on the use of resol phenol-formaldehyde or resol modified phenol-formaldehyde resins to produce particleboards, where different resin preparation and particles moisture content (Cetin and Ozmen 2002; Czarnecki and Lecka 2002, Dukarska and Lecka 2006; Pizzi 2003). In these

studies were used hot platen press with a pressing factor between 5 and $12 \mathrm{~s} \mathrm{~mm}^{-2}$, depending on the pressing time used and the desired moisture panel (Pizzi 2003). Usually the platen temperature used is between 180 and $220^{\circ} \mathrm{C}$, pressures in the 25 and $35 \mathrm{~kg} \mathrm{~cm}^{-2}$ and pressing time are between 8 and 12 min (Czarnecki and Lecka 2002; Pizzi, 2003).

The main purpose of this study is to develop a PF resin for wood-based panels production with good physic mechanical performance that satisfies formaldehyde emission restrictions and LEED criteria, by changing some process variables during the synthesis process, as well as some changes on the resin formulation for the particleboard production.

\section{Materials and methods}

\section{Preparation of PF resin}

All resins were synthesised in round bottom flasks with $5 \mathrm{~L}$ volume, equipped with mechanical stirring and a thermometer. Temperature control was accomplished by means of a heating blanket. $\mathrm{pH}$ and viscosity measurements are performed off-line, on samples taken from the reaction mixture. The resins were synthesised according to the conventional process in which the methylolation and condensation step both occurs at alkaline conditions. The process begins with the methylolation/condensation reaction between a $40 \%$ formaldehyde solution and a 90\% phenol solution, at an alkaline $\mathrm{pH}$ - between 9 and 10 - by adding an appropriate amount of sodium hydroxide. In the methylolation step the initial attack may be at the 2-, 4- and 6- position of the phenolic ring (Fig. 2). The formaldehyde solution is added 
gradually, allowing the heat of reaction to raise temperature from the initial $60^{\circ} \mathrm{C}$ to values between 95 and $100^{\circ} \mathrm{C}$. The amount of formaldehyde solution added to the phenol solution is sufficient to provide a formaldehyde/phenol molar ratio (F/P) of 1-8.

The condensation step involves the reaction of the methylol groups with other available phenol or methylolphenol, leading first to the formation of linear polymers and then to the formation of hard-cured, highly branched structures (Fig. 3).

This reaction proceeds until a desired viscosity is attained, between 400 and $600 \mathrm{cP}$, and is terminated by cooling of the resin to a temperature of $50^{\circ} \mathrm{C}$. At this temperature a determined amount of sodium hydroxide is added to guaranty that the final resin $\mathrm{pH}$ is between 11 and 12. The reaction is finally terminated by cooling the reaction mixture to a temperature of $25^{\circ} \mathrm{C}$.

\section{Resin properties determination}

Viscosity, $\mathrm{pH}$, alkaline content (defined as the amount of base added during resin synthesis), water tolerance, free phenol and solid content were determined at the end of each synthesis. Viscosity was measured with a Brookfield viscometer at $25 \mathrm{uC}$ and expressed in $\mathrm{cP}$. The resin $\mathrm{pH}$ was measured at $25^{\circ} \mathrm{C}$ using a combined glass electrode. The solid content was determined by evaporation of volatiles in $2 \mathrm{~g}$ of resin for $2 \mathrm{~h}$ at $135^{\circ} \mathrm{C}$ and expressed in $\%$. The alkaline content was determined by potentiometric neutralization of a solution to a $\mathrm{pH}$ of 7 , using a strong acid. The free phenol content was determined with gas chromatography and is expressed in \%. The water tolerance (\%) was determined, by the amount of water that is possible to add to a $5 \mathrm{~g}$ of resin until this solution turns hazy.

\section{Particleboard production}

The production of particleboards is essentially divided into four stages: preparation of raw materials, blending, mat formation and pressing. Wood particles were provided by Sonae Indústria, Oliveira do Hospital. Standard particle mixtures were used for the core and face layers, which are composed of different proportions of pine, eucalypt, pine sawdust and recycled wood. The moisture content of the standard mixtures was checked before blending. The average moisture content of the face and core layers particles was 2-5 and 3-5\% respectively. Wood particles were then blended with resin, hardener and paraffin in a laboratory glue blender. The gluing factor was $7 \%$ resin solids in the face and between 4 and $6 \%$ in the core, based on the oven-dry weight of wood particles. The hardener content in the core layer was higher (between 5 and 10\% solids based on oven-dry weight of resin) than in the face layer (1\% solids based on oven-dry weight of resin). The paraffin level was $0 ? 1 \%$ solids (based on oven-dry weight of wood).

Three-layer particleboard was hand formed in an aluminium container with 2206220680 $\mathrm{mm}$. The total percentages of board mass were: $20 \%$ for the upper face layer, $62 \%$ for the core layer and for $18 \%$ bottom face

layer. Boards were pressed in a laboratory scale hot- press, controlled by a computer and equipped with a displacement sensor (LVDT), thermocouples and pressure transducers. The glued particles were pressed at $190^{\circ} \mathrm{C}$, with pressing times between 150 and $300 \mathrm{~s}$ to produce panels with a target density of $650 \mathrm{~kg} \mathrm{~m}^{-3}$ and thickness of $17 \mathrm{~mm}$.

Determination of internal bond strength and formaldehyde content

After pressing, boards were stored in a conditioned room (20uC, $65 \%$ relative humidity) and 
then tested according to the European standards. The internal bond strength (IB) was determined according to EN 319 (tensile strength perpendicular to the plane of the board) and the formaldehyde content was determined according to EN120 (perforator method). Panels for the formaldehyde content analysis were stored in sealed plastic bags.

\section{Results and discussion}

In this study, we set out to produce a resol PF resin for particleboard production, with low formaldehyde emission and for interior use. For particleboard production it is necessary that the final resin viscosity varies between $300-500 \mathrm{cP}$ in order to avoid high penetration on the wood chips. The resin must also have high water tolerance (an indication of the miscibility of the resin with water) due to the fact that for particleboard production the resin may be diluted with water up to $100 \%$. Another important aspect is the final phenol content, which must be as low as possible.

\section{Resin synthesis process - effect of alkaline content}

Initially two resins with different alkaline content (amount of sodium hydroxide added) were synthesised. In Resin A, 4\% sodium hydroxide was added, based on the total amount of resin, while in Resin B the added amount was 9\% (both values based on the total weight of the resins). The remaining process variables were the same for both resins, and their final F/P molar ratio was 1-8. Table 1 shows the physico-chemical properties of the two resins. The biggest difference between these two resins is the free phenol content, which is highly related with the amount of sodium hydroxide added in each resin. The final $\mathrm{pH}$ and water tolerance are also different for both resins due to the different amounts of sodium hydroxide added. In both resins the total amount of sodium hydroxide added was divided between the beginning and end of the synthesis period. The amount added in the beginning is essentially to promote the reaction of the formaldehyde and phenol in an alkaline environment (between pH 8 and 9). The final sodium hydroxide allows resin stabilisation in terms of molecular weight, viscosity, and water tolerance. This stabilization by sodium hydroxide addition is a consequence of the high solubility of this type of resins in strong alkali solutions (Pizzi 2003). However, in this case, the quantity of base added is only enough to promote the dissolution of the high molecular weight polymer and to increase the water tolerance of the final resin. Therefore, an important relationship is here present between water tolerance and molecular weight: lower molecular weight translates into higher water tolerance (Fink 2005).

For both resins the amount of sodium hydroxide added in the beginning of the synthesis is the same, so the differences are found on the final addition. In the case of Resin A, the final sodium hydroxide was added all at once when the resin reached a viscosity between 400 and $700 \mathrm{cP}$. However, in the case of Resin B, the higher amount of sodium hydroxide was added stepwise. This approach avoided a substantial decrease in viscosity and has allowed a higher consumption of phenol and formaldehyde in the condensation reaction, without formation of high molecular weight polymer, since the water tolerance was always higher than $500 \%$ throughout the condensation reaction.

Figure 4 shows the viscosity evolution during the condensation reaction for both resins. For Resin A the viscosity increases continuously during the condensation reaction, after the initial sodium hydroxide addition. On the other hand, during condensation reaction of Resin $\mathrm{B}$, the sodium hydroxide additions (at 20 min intervals) originated a decrease in viscosity, 
followed by a rise as the reaction proceeded. It is also possible to see that this modification on the synthesis process resulted in an increase of $30 \mathrm{~min}$ on the duration of the condensation reaction.

One of the biggest problems of PF resins is their low stability over time. In order to evaluate the stability, these resins were stored at $25 \mathrm{uC}$ during 21 days. The viscosity evolution over time is presented in Fig. 5. It is possible to see that Resin B, with the higher final alkaline content, presented greater stability than Resin A, which had a viscosity increase from around 500 to $1000 \mathrm{cP}$ in just 21 days. On the other hand, viscosity of Resin B only increased $60 \mathrm{cP}$ during the same amount of time. This fact can be explained by the different water tolerance of both resins, which indicates a difference in their molecular weight. It is known that the higher the molecular weight of a resin, the lower is its water tolerance and storage stability (Fink 2005; Pizzi 2003). Since Resin B had water tolerance at least four times higher than the water tolerance of Resin A, it was expected that it would have better stability. With regard to $\mathrm{pH}$, it remained constant during the stability period. On the other hand, it was possible to observe a colour change from a light-red (obtained at the end of the synthesis) to darkbrown (obtained at the end of the stability period), this being more evident in the Resin A.

\section{Particleboard evaluation - effect of amount of hardener and resin}

For the particleboard production only Resin A and B were used. Initially a series of particleboard panels were produced with these resins using different pressing times (between 150 and $300 \mathrm{~s}$ ). The amount of resin used in the core layer was $4.5 \%$ (based on the oven dry weight of wood particles) and the amount of hardener was $5 \%$ (based on the oven dry weight of the resin). The hardener used was a $50 \%$ solution of potassium carbonate.

The results, presented in Table 2, are very clear and show that the presence of a higher value of alkaline content is better for the physico-mechanical properties. All boards made with Resin A present very low values of internal bond strength. However, the Resin B boards showed values between 0 and $0-50 \mathrm{~N} \mathrm{~mm}^{-2}$.

In order to identify the best conditions for blending and pressing of the wood particles, a series of particle-boards panels were produced using different amounts of resin and hardener in the core layer particles. It was used different pressing times too. Table 3 shows the four different conditions used. The amount of resin is based on the oven dry weight of wood particles and the amount of hardener is based on the oven dry weight of resin.

Figure 6 shows the results for the internal bond strength for different pressing times. As shown in this figure, for all conditions, lower pressing time values result in lower internal bond strength values. Better results were found for the two series of boards that were produced with a higher amount of hardener, but the best value is the one with simultaneously the highest amount of resin and hardener. Since the main objective is to produce boards with the

minimum acceptable value of $0-35 \mathrm{~N} \mathrm{~mm}^{-2}$ (the requirement for type $\mathrm{P} 2$ boards according to EN 312 standard), it is possible to claim that, under these conditions, a pressing time between 270 and $300 \mathrm{~s}$ is needed to obtain boards with good quality.

\section{Resin B synthesis process reproducibility}

In order to prove the reproducibility of the Resin B synthesis process, three new resins were synthesised. Table 4 shows the results for the physico-chemical properties of these three resins. As it is possible to see, all resins are very similar and the difference in the final 
viscosity is acceptable (the objective was to obtain a resin with a viscosity between 400 and $600 \mathrm{mPa} \mathrm{s}$ ).

In terms of synthesis process all resins had a similar behaviour, either during the initial reaction, as well as during the stepwise addition of sodium hydroxide, as it is possible to see in the Fig. 7.

Regarding the stability of these resins (Fig. 8), this was followed throughout 1 month and it was found small increases in viscosity, behaviour similar in all aspects to the one observed in the Resin B.

For particleboard production with these three resins, the conditions C4 (5\% resin and $10 \%$ hardener) and pressing time between 210 and $300 \mathrm{~s}$ were chosen. For the formaldehyde determination it was used the panels produced with pressing times of $300 \mathrm{~s}$ were used. The physico-mechanical properties of these three resins are presented in Table 5.

As we can see the three resins are very similar for both properties and it can be said that the synthesis process is reproducible. Resin B2 and B3 presents values higher than the acceptable minimum of $0-35 \mathrm{~N} \mathrm{~mm}^{-2}$ for the panels produced with pressing time of 270 $\mathrm{s}$. For a pressing time of $300 \mathrm{~s}$ this minimum is also achieved. The values of formaldehyde content are also below the maximum acceptable of $2-7 \mathrm{mg} / 100 \mathrm{~g}$ oven dry board specified by the Japanese $\mathrm{F}^{* * * *}$ legislation (Marutzk 2008). These lower values of formaldehyde content can be easily related to the lower phenol content, since they were both highly consumed during the sodium hydroxide addition on the condensation reaction.

\section{Conclusion}

With this study it was possible to conclude that the presence of a higher amount of base in the final phenol- formaldehyde resin results in higher storage stability and improved physicomechanical properties. At the same time, base addition leads to a resin with low content of phenol, due to its higher consumption during the condensation step.

The results obtained from particleboard production showed that simultaneously good internal bond strength and reasonable board pressing times can be achieved using the following conditions in particleboard production: $10 \%$ hardener (based on oven-dry weight of resin) and gluing factor between $4-5-5 \%$ on the core layer. The best performing resin obtained in this study, Resin B, showed very good values for internal bond strength and formaldehyde content, allowing its use of in the so called 'Green Building' construction.

\section{Acknowledgements}

This work is co-founded by FEDER/QREN (E0_ formaldehyde project with reference FCOMP010202FE DER005347) in the framework of 'Programa Operacional Factor de Competitividade'.

The authors wish to thank EuroResinas (Sonae Indústria) and Sonae Indústria PCDM for providing the equipment and raw materials needed for this work. Nádia Paiva wishes to thank FCT - Foundation for Science and Technology and EuroResinas (Sonae Indústria) for the PhD grant with reference SFRH/BDE/51294/2010. 


\section{References}

Caesar, C. and Sachanen, A. N. 1948. Triophene-formaldehyde condensation. Industr. Chem. Eng. 40(5): 922-928.

Çetin, N. S. and Ö zmen, N. I. 2002. Use of organosolv lignin in phenol-formaldehyde resins for particleboard production: II. Particle- board production and properties. Int. J. Adhes. Adhes. 22(5): 481-486.

Czarnecki, R. and Leck, A. J. 2002. H2O2 as a modifier of phenol- formaldehyde resin used in the production of particleboards. J. Appl. Polym. Sci. 88: 3084-3092.

Dukarska, D. and Lecka, J. 2006. Optimization of the process of pressing particleboards by means of modifying phenol-formalde- hyde resin with amide polymers. Holz als Roh und Werkstoff 64(5): 403-409.

Fink, J. K. 2005. Phenol/formaldehyde resins: reactive polymers fundamentals and applications - a concise guide to industrial applications. Plastics Design Library, Elsevier, 241-281.

IARC. 2006. Formaldehyde, 2-Butoxyethanol and 1-Tert-Butoxypropan- 2-OL: International Agency for Research on cancer mono- graphs on the evaluation of carcinogenic risks to humans 88: 37-327.

Kamoun, C. and Pizzi, A. 2000. Mechanism of hexamine as a non- aldehyde polycondensation resins hardener - part 1. Holzforschung Holzverwertung 52(1): 16-18.

Kamoun, C. and Pizzi, A. 2000. Mechanism of hexamine as a non- aldehyde polycondensation resins hardener - part 2. Holzforschung Holzverwertung 52(1): 66-67.

Knop, A. and Scheib, W. 1979. Chemistry and application of phenolic resins. Berlin/Heilderberg/New York: Springer-Verlag.

Lee, J.-U. and Oh Y.-S. 2010. Properties of particleboard produced with liquefactionmodified phenol-formaldehyde adhesive. Turkish J. Agricult. Forestry 303-308.

LEED. 2011. LEED 2009 - For Commercial Interiors Rating System.

MARUTZK R (2008). Proceedings of 6th European Wood-Based Panel

Symposium, Hannover, Germany.

Pizzi, A. 2003. Phenolic resins adhesives: handbook of adhesive technology. Marcel Dekker.

SRI. 2011. Phenolic Resins, SRI Consulting.

USDHHS. 2011. Report on Carcinogens: 12th edn, U.S. Department of Health and Human Services, Public Health Service, National Toxicology Program.

Whitehouse, A. A. K., Princhett, E. G. K. and Barnett, G. 1967. Phenolic Resins: Plastic Institute. London: ILIFFE Books Ltd. 
1 Structure of Novolac and Resol Resins

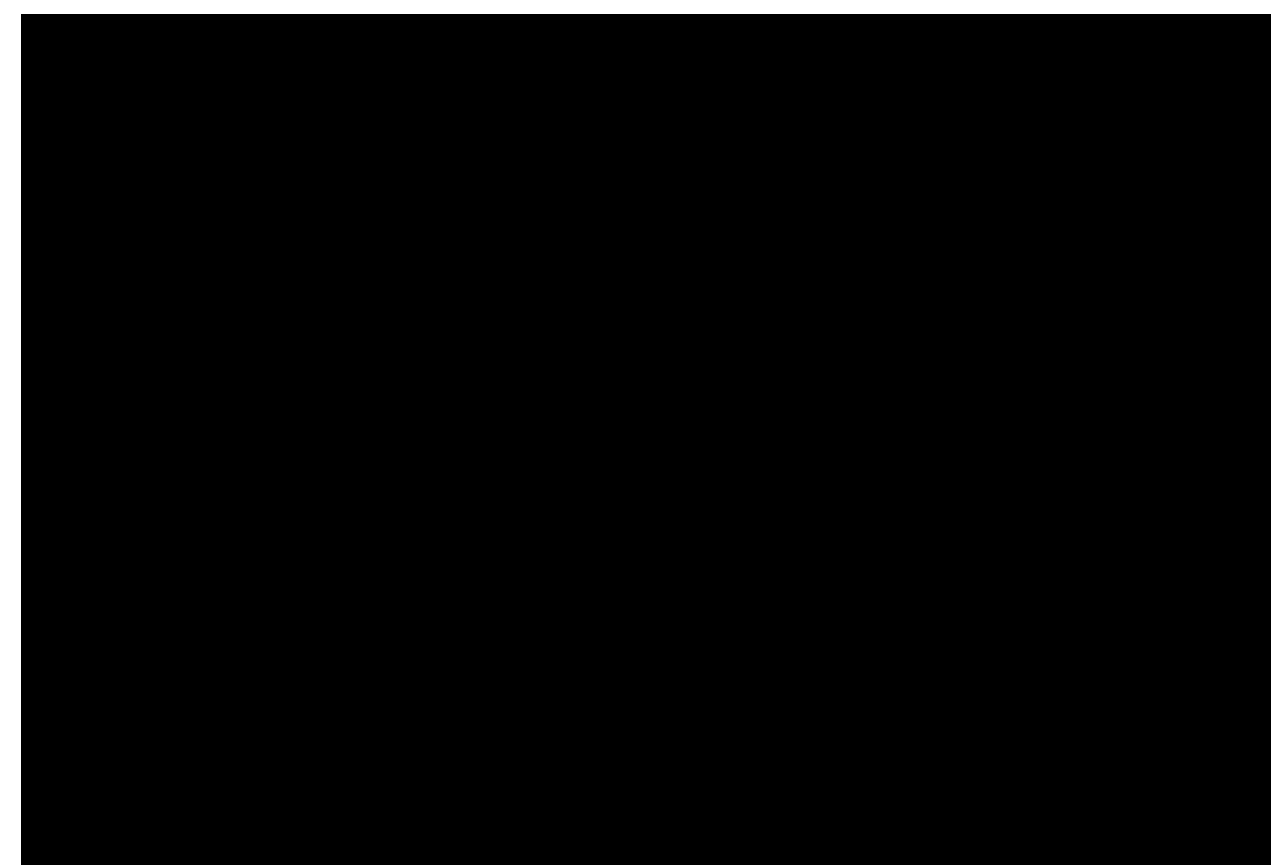

2 Formation of methylolphenols (mono-, di- and tri) by addition of formaldehyde to phenol

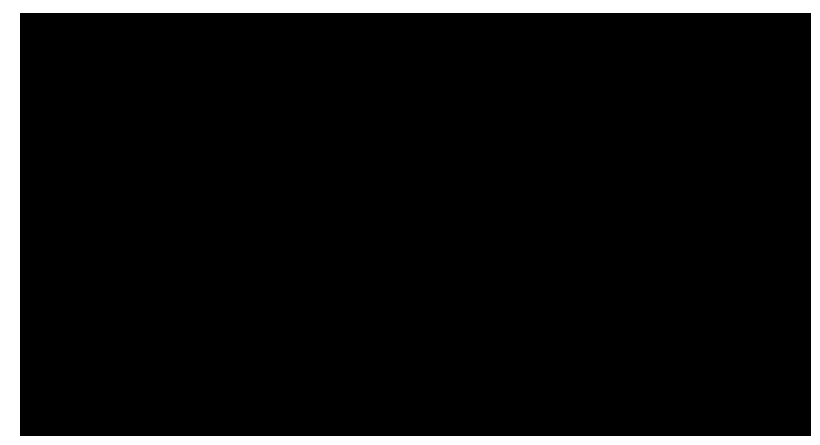

3 Methylolphenols condensation in order to create a phenol formaldehyde network polymer 


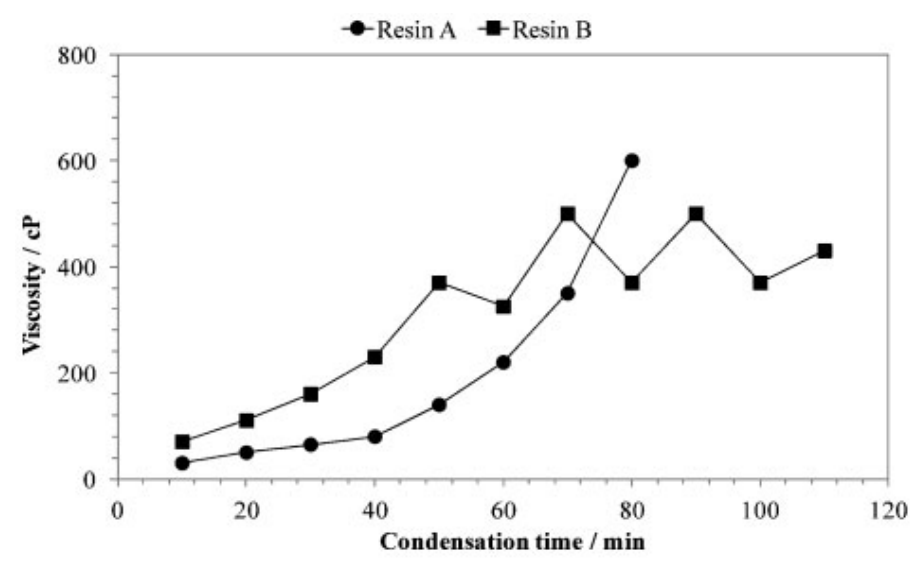

4 Development of viscosity during condensation reaction for Resins A and B

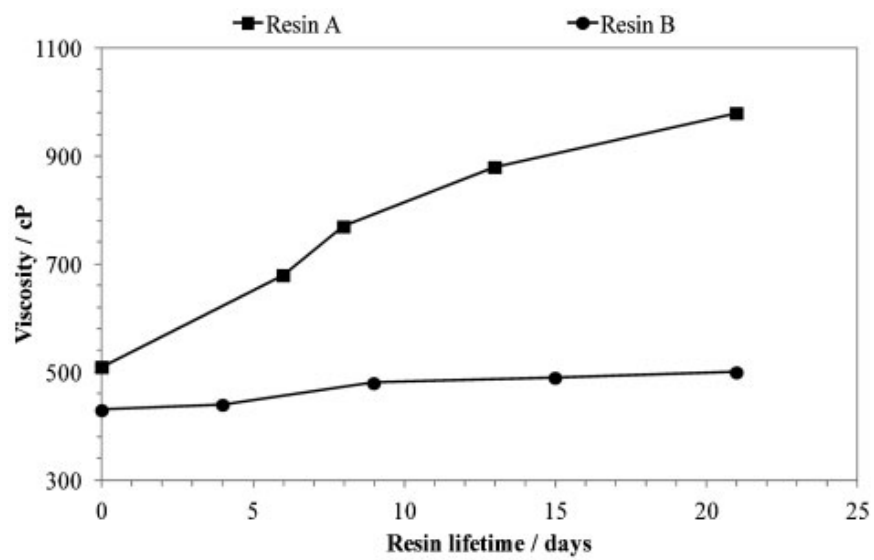

5 Resin viscosity evolution during 21 days (Resin A - 4\% alkaline content; Resin B $-8 \%$ alkaline content)

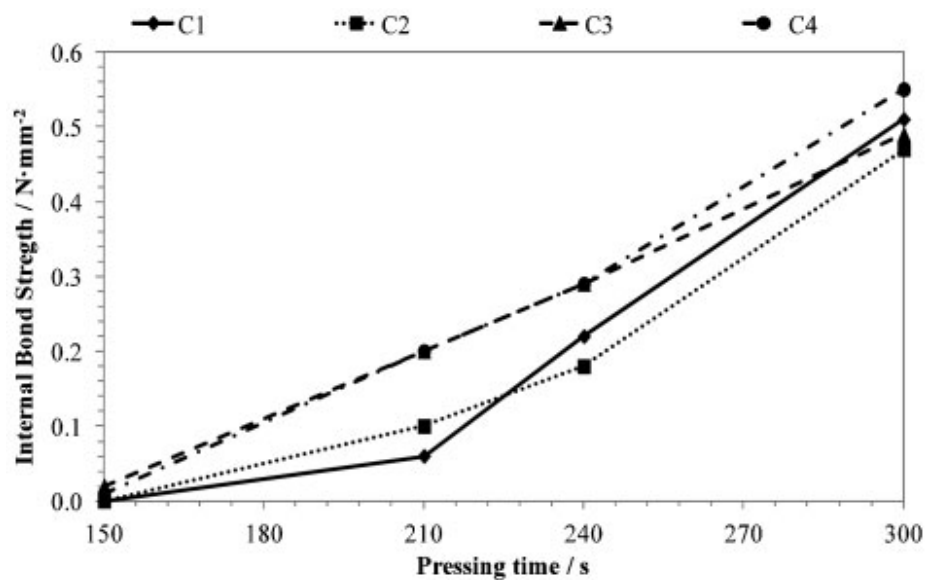

6 Internal Bond Strength variation with pressing time using four different conditions 


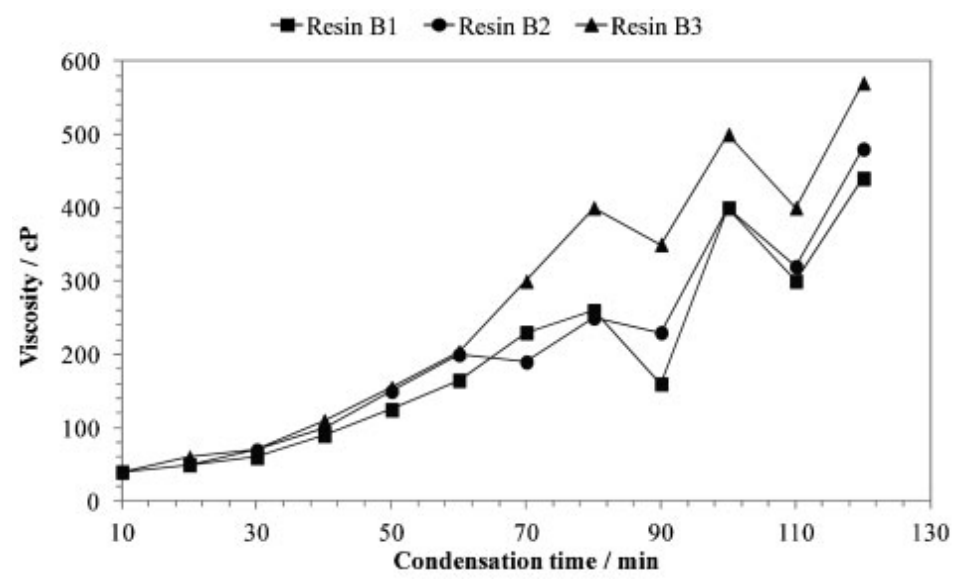

7 Development of viscosity during condensation reaction for Resins B1, B2 and B3

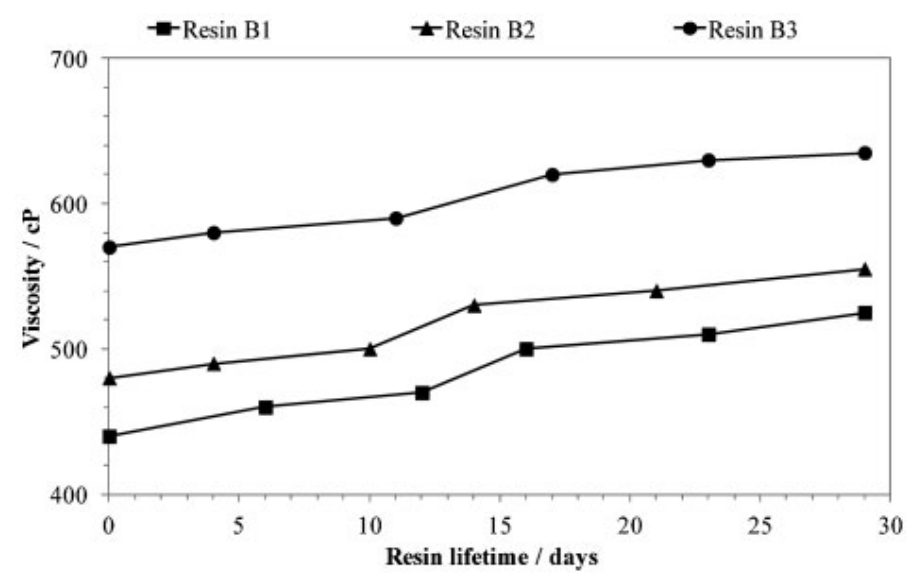

8 Resin B1, B2 and B3 viscosity evolution during one month

Table 1 Resins A and B final properties

\begin{tabular}{lcc} 
Properties/resin & A & B \\
\hline Solids content/\% & 50.02 & 49.90 \\
Alkaline content/\% & 3.6 & 8.8 \\
Final pH & 10.52 & 12.21 \\
Final viscosity/mPa s & 500 & 430 \\
Free phenol/\% & 1.02 & 0.22 \\
Water tolerance/\% & 500 & $>2000$ \\
\hline
\end{tabular}


Table 2 Internal bond strength results for Resin A and B produced with different pressing times

\begin{tabular}{lll}
\hline Pressing time/s & Resin A & Resin B \\
\hline 150 & 0.00 & 0.00 \\
210 & 0.01 & 0.10 \\
240 & 0.03 & 0.18 \\
300 & 0.14 & 0.47 \\
\hline
\end{tabular}

Table 3 Blending conditions for particleboard production optimization

\begin{tabular}{lll}
\hline Condition & Amount of resin/\% & Amount of hardener/\% \\
\hline C1 & 4.5 & 5 \\
C2 & 5.0 & 5 \\
C3 & 4.5 & 10 \\
C4 & 5.0 & 10 \\
\hline
\end{tabular}

Table 4 Properties of PF resins produced with $9 \%$ alkaline content

\begin{tabular}{lccc}
\hline Properties/resin & B1 & B2 & B3 \\
\hline Solids content/\% & 49.95 & 49.88 & 50.12 \\
Alkaline content/\% & 8.0 & 7.8 & 7.5 \\
Final pH & 12.20 & 11.96 & 11.75 \\
Final viscosity/mPa s & 440 & 480 & 570 \\
Free phenol/\% & 0.40 & 0.28 & 0.30 \\
Water tolerance/\% & $>2000$ & $>2000$ & $>2000$ \\
\hline
\end{tabular}

Table 5 Resins B1, B2 and B3 particleboard properties with conditions C4

\begin{tabular}{lllll}
\hline Properties/Resin & Pressing time/s & Resin B1 & Resin B2 & Resin B3 \\
\hline Internal bond strength/N mm & & & & \\
& 210 & 0.04 & 0.22 & 0.11 \\
& 240 & 0.19 & 0.25 & 0.20 \\
Formaldehyde Content (mg/100 g oven dry board) & 270 & 0.24 & 0.46 & 0.42 \\
& 300 & 0.43 & 0.54 & 0.50 \\
\hline
\end{tabular}

